\title{
Recent advances in rehabilitation of stroke survivors
}

\section{Veronika I Skvortsova and Elena A Kovrazhkina*}

\author{
Address: Russian State Medical University, 1 Ostrovitjanova Street, 117997, Moscow, Russia \\ *Corresponding author: Elena A Kovazhkina (ekovrazh1@pochta.ru) \\ Fl000 Medicine Reports 2009, I:23 (doi: 10.3410/MI-23)
}

The electronic version of this article is the complete one and can be found at: http:/FI000.com/Reports/Medicine/content/I/23

\begin{abstract}
This report discusses the newest approaches to rehabilitation of post-stroke patients. Recent studies have clinical implications for the treatment of stroke at all stages, and chronic aphasia.
\end{abstract}

\section{Introduction and context}

The studies conducted on post-stroke rehabilitation in recent years can be divided into two groups. The first group concerns neurorehabilitation in the acute period of stroke, when beginning rehabilitation as early as possible is still considered the most important element. The second group deals with the possibilities of neurorehabilitation in the subacute and chronic periods, where it is currently considered most important to correctly estimate the rehabilitation potential of the patient.

\section{Recent advances}

The majority of modern movement rehabilitation techniques are tested and recommended for chronic stroke patients. Beginning rehabilitation interventions within 3 months after stroke is considered the most effective practice, but has certain restrictions. A recent review by Cramer [1] suggested that such restrictions include 'clinical traditions' and objective difficulties such as a lack of facilities for early rehabilitation. At further stages priority is given to 'restorative' therapies, among which the author notes the use of growth factors, cellbased therapies, electromagnetic stimulation, devicebased strategies, and task-oriented and repetitive training-based interventions [1].

The majority of these rehabilitation techniques are based on the phenomenon of neural plasticity. There are many recent studies devoted to fundamental research of this phenomenon [2,3]. For instance, good neurological and functional restoration was demonstrated in patients who have suffered spinal trauma, even with remaining damage to the cortico-spinal tract (determined using motor and somato-sensory evoked potentials) [2]. Studies performed on monkeys in the late restoration period of stroke have shown growth of the ventral and dorsal premotor areas representing the paretic upper limb, which correlated with the infarction volume and the level of functional improvement [3].

Movement rehabilitation techniques that are aimed at neural plasticity include task-specific techniques, based not on training of separate movements, but of the movement pattern as a whole: treadmills with body weight support, robotic ortheses for upper and lower limbs, virtual reality technologies, functional (programmed) electromyostimulation and electroneurostimulation, and transcranial magnetic stimulation $[1,4,5]$.

Recent studies in patients with acute stroke are still concerned with beginning rehabilitation as early as possible. Thus, they have shown the efficacy and safety of getting stroke patients out of bed within the first 24 hours after onset [6]. The same authors have shown in a comparative study, however, that this base requirement is currently not carried out in all stroke units [7].

Another important problem in the acute period of stroke remains the selection of candidates for further active rehabilitation. The use of Activities of Daily Living (ADL) scales (such as the Barthel Index, the Modified Rankin Scale and the Rivermead Mobility Index), has been previously recommended to assess functional status [8]. 
Recently, new methods have been proposed for evaluating 'reserve' neural plasticity by means of hi-tech techniques, including functional magnetic resonance imaging (fMRI) and transcranial magnetic stimulation [9]. The data obtained using these techniques show that the period of active rehabilitation can exist for up to 3 years after stroke [9].

There are a small number of studies that have shown the limitations of modern hi-tech task-specific techniques. For example, robotic training devices and functional electromyostimulation and electroneurostimulation cannot provide natural patterns of muscular activity [10-12]. Thus, many techniques are more effective in combination: the robotic orthosis 'Gait Trainer' combined with functional electromyostimulation, botulinum toxin injections combined with physiotherapy exercises, as well as electromyo(neuro)stimulation and cyclic training devices $[13,14]$.

Training based on modern hi-tech techniques use multiple repetitions of movements. To accommodate this, simple and low-cost systems are being developed that can be used by patients at home: robotic devices such as the LokoHelp, which provides patients with a walking type motion alone, functional electromyostimulation, and virtual reality methods based on the Sony PlayStation 2 [5].

There are still problems in neurorehabilitation that concern the diagnosis and treatment of particular poststroke syndromes. A study by Polanowska et al. estimated the efficacy of electrostimulation for correction of left-sided visual-spatial neglect [15]. The work demonstrated that the technique had a delayed, but significant effect. The study by Spitzyna et al. demonstrated that optokinetic therapy (involuntary saccades) had a significant corrective effect on the problem of hemianopic alexia [16]. Another recent study by Alibiglou et al. found that the Modified Ashworth scale, which is widely used in evaluating spasticity, is unreliable, and proposed a new method for differentiated evaluation of neural and musculotendinous components of spasticity [17].

In rehabilitation of speech disorders (aphasia) the most widely used approach is still based on high intensity training (prolonged and frequent exercises). The efficacy of intense speech rehabilitation is supported by fMRI data $[18,19]$. Based on fundamental neuroscience developments, Pulvermüller and Berthier have formulated three main principles of aphasia rehabilitation: (1) intensity of training, (2) behavioural and communicational relevance of the tasks in relation to the patient,
(3) focus of the training on the communication needs and capabilities of the patient [19]. The authors used these three principles as a basis for 'intensive language-action therapy' (ILAT), which was proven to be highly effective in chronic aphasia rehabilitation [19]. For chronic aphasia cases when restoration of speech is impossible, visual communication aids are being developed. [20].

The efficacy of pharmacological agents in restoration therapy, including rehabilitation of aphasia, remains a subject of ongoing research. Currently glutamatergic, monoaminergic and cholinergic agents are being studied, but for the moment there is no clear evidence showing their efficacy [21].

\section{Implications for clinical practice}

In summary, recent advances have suggested several changes in the way we rehabilitate stroke patients. In the acute phase, mobilization of stroke patients in the first 24 hours has been shown to be important [6], as has the use of fMRI to select patients in the subacute and chronic periods who may benefit from therapy. Recent studies also suggest that using multiple rehabilitation techniques in combination are generally more effective than using a single technique $[13,14]$. Other clinical advances include the demonstration that electrostimulation is beneficial in left-sided visual-spatial neglect [15], and that optokinetic therapy (involuntary saccades) can help to correct hemianopic alexia.

In the rehabilitation of chronic aphasia, the new principles of 'intensive language-action therapy' have proven highly effective. We hope that ongoing intensive research will continue to produce further clinical advances.

\section{Abbreviations}

fMRI, functional magnetic resonance imaging.

\section{Competing interests}

The authors declare that they have no competing interests.

\section{References}

I. Cramer SC: Repairing the human brain after stroke. II. Restorative therapies. Ann Neurol 2008, 63:549-60.

FI000 Factor 3.0 Recommended

Evaluated by Anna Czlonkowska II Jun 2008

2. Curt A, Van Hedel HJ, Klaus D, Dietz V; EM-SCI Study Group: Recovery from a spinal cord injury: significance of compensation, neural plasticity, and repair. J Neurotrauma 2008, 25:677-85. FI000 Factor 3.0 Recommended Evaluated by David Choi with Carolina Kachramanoglou 26 Aug 2008 
3. Eisner-Janowicz I, Barbay S, Hoover E, Stowe AM, Frost SB, Plautz EJ, Nudo RJ: Early and late changes in the distal forelimb representation of the supplementary motor area after injury to frontal motor areas in the squirrel monkey. J Neurophysiol 2008, 100:1498-512.

FI000 Factor 3.0 Recommended

Evaluated by Heidi Johansen-Berg with Charlotte Stagg 30 Sep 2008

4. Hesse S, Schmidt H, Werner C: Machines to support motor rehabilitation after stroke: 10 years of experience in Berlin. J Rehabil Res Dev 2006, 43:67I-8.

5. Flynn S, Palma P, Bender A: Feasibility of using the Sony PlayStation 2 gaming platform for an individual poststroke: a case report. J Neurol Phys Ther 2007, 3 I: 180-9.

6. Bernhardt J, Dewey H, Thrift A, Collier J, Donnan G: A very early rehabilitation trial for stroke (AVERT): phase II safety and feasibility. Stroke 2008, 39:390-6.

FI000 Factor 6.0 Must Read

Evaluated by Veronika Skvortsova with Elena Kovrazhkina 19 May 2008

7. Bernhardt J, Chitravas N, Meslo IL, Thrift AG, Indredavik B: Not all stroke units are the same: a comparison of physical activity patterns in Melbourne, Australia, and Trondheim, Norway. Stroke 2008, 39:2059-65.

FI000 Factor 3.0 Recommended

Evaluated by Veronika Skvortsova with Elena Kovrazhkina 28 Aug 2008

8. Duncan PW, Zorowitz R, Bates B, Choi JY, Glasberg J], Graham GD, Katz RC, Lamberty K, Reker D: Management of Adult Stroke Rehabilitation Care: a clinical practice guideline. Stroke 2005, 36:100-43.

9. Stinear CM, Barber PA, Smale PR, Coxon JP, Fleming MK, Byblow WD: Functional potential in chronic stroke patients depends on corticospinal tract integrity. Brain 2007, 130:170-80.

FI000 Factor 3.0 Recommended

Evaluated by Nick Ward I3 Aug 2008

10. Hidler JM, Wall AE: Alterations in muscle activation patterns during robotic-assisted walking. Clin Biomech 2005, 20:184-93.

II. Regnaux JP, Saremi K, Marehbian J, Bussel B, Dobkin BH: An accelerometry-based comparison of 2 robotic assistive devices for treadmill training of gait. Neurorehabil Neural Repair 2008, 22:348-54.
12. Bogey R, Hornby GT: Gait training strategies utilized in poststroke rehabilitation: are we really making a difference? Top Stroke Rehabil 2007, 14: I-8.

13. Tong KY, Ng FW, Li SW, So FM: Ambulation training for patients with acute stroke by Gait Trainer cyclic walking exercise and Functional Electrical Stimulation (FES): a pilot study. In 10th Annual Conference of the International FES Society. Montreal, Canada; July 2005.

14. Johnson CA, Burridge JH, Strike PW, Wood DE, Swain ID: The effect of combined use of botulinum toxin type $A$ and functional electric stimulation in the treatment of spastic drop foot after stroke: a preliminary investigation. Arch Phys Med Rehabil 2004, 85:902-9.

15. Polanowska K, Seniow J, Paprot E, Leśniak M, Członkowska A: Lefthand somatosensory stimulation combined with visual scanning training in rehabilitation for post-stroke hemineglect: $\mathrm{A}$ randomised, double-blind study. Neuropsychol Rehabil 2008, 26: I.

FI000 Factor 3.0 Recommended Evaluated by Argye Hillis 2 Sep 2008

16. Spitzyna GA, Wise RJ, McDonald SA, Plant GT, Kidd D, Crewes $H$, Leff AP: Optokinetic therapy improves text reading in patients with hemianopic alexia: a controlled trial. Neurology 2007, 68: 1922-30.

FI000 Factor 6.0 Must Read Evaluated by Caroline Tilikete with Alain Vighetto 16 Sep 2008

17. Alibiglou L, Rymer WZ, Harvey RL, Mirbagheri MM: The relation between Ashworth scores and neuromechanical measurements of spasticity following stroke. J Neuroeng Rehabil 2008, 5: 18.

FI000 Factor 3.0 Recommended

Evaluated by Veronika Skvortsova with Elena Kovrazhkina 17 Sep 2008

18. Harnish SM, Neils-Strunjas J, Lamy M, Eliassen JC: Use of fMRI in the study of chronic aphasia recovery after therapy: a case study. Top Stroke Rehabil 2008, I5:468-83.

19. Pulvermüller F, Berthier ML: Aphasia therapy on a neuroscience basis. Aphasiology 2008, 22:563-99.

20. Johnson RK, Hough MS, King KA, Vos P, Jeffs T: Functional communication in individuals with chronic severe aphasia using augmentative communication. Augment Altern Commun 2008, 24:269-80.

21. Liepert J: Pharmacotherapy in restorative neurology. Curr Opin Neurol 2008, $21: 639-43$. 